\title{
ANALISIS VEGETASI DI TAMAN WISATA ALAM (TWA) SUNGAI DUMAI, RIAU
}

\section{Analysis Of Vegetation Density In TWA Sungai Dumai, Riau}

\author{
Hanifah Ikhsani ${ }^{1}$ \\ ${ }^{1)}$ Staff Pengajar Fakultas Kehutanan Universitas Lancang Kuning \\ Jln. Yos Sudarso Km. 8 Rumbai Pekanbaru Riau \\ E-mail: hanifah@unilak.ac.id
}

Diterima: 15 Desember 2020, Direvisi: 21 Desember 2020, Disetujui: 21 Januari 2021

DOI: $10.31849 /$ forestra.v16i1.5720

\begin{abstract}
TWA Sungai Dumai is a tourist forest area and ensuring the preservation of natural potential. However, there are problems that can disrupt the sustainability of it, including forest and land fires and conversion of land use to agriculture and oil palm plantations. Until now, there is no vegetation analysis using satellite imagery in TWA Sungai Dumai, so it is important to do so that can be managed sustainably. This study aims to make a classification of vegetation density classes which are presented in the form of a vegetation density class map in it. This research uses Landsat-8 OLI / TIRS images from October 2017 and October 2020 which are processed to determine density class using Normalized Difference Vegetation Index algorithm. The vegetation density class with the highest area in 2017 was the vegetation density class $(2380,832$ ha or $66,819 \%$ of the total area), while the lowest area was the nonvegetation class $(75,737$ ha or $2,126 \%$ of the total area). The vegetation density class with the highest area in 2020 in TWA Sungai Dumai is dense vegetation density class $(3205,039$ ha or $89,950 \%$ of the total area), while the lowest area is non-vegetation class $(1,637$ ha or $0.046 \%$ of the total area).
\end{abstract}

Keywords : NDVI, TWA Sungai Dumai, Vegetation density

\section{ABSTRAK}

TWA Sungai Dumai merupakan kawasan hutan wisata yang memiliki panorama alam yang indah sehingga dapat dimanfaatkan bagi kepentingan rekreasi alam serta menjamin kelestarian potensi alam. Akan tetapi, terdapat permasalahan yang dapat mengganggu kelestariannya, yaitu kebakaran hutan dan lahan dan alih fungsi lahan menjadi pertanian dan kebun sawit. Hingga saat ini, analisis vegetasi menggunakan citra satelit di TWA Sungai Dumai belum ada, sehingga penting dilakukan agar TWA Sungai Dumai dapat dikelola secara lestari. Penelitian ini bertujuan untuk membuat klasifikasi kelas kerapatan vegetasi yang disajikan berupa peta kelas kerapatan vegetasi di TWA Sungai Dumai. Penelitian ini 
menggunakan citra Landsat-8 OLI/TIRS Perekaman Oktober 2017 dan Oktober 2020 yang diproses untuk menentukan kelas kerapatan menggunakan algoritma Normalized Difference Vegetation Index. Kelas kerapatan vegetasi dengan luas tertinggi pada tahun 2017 di TWA Sungai Dumai adalah kelas kerapatan vegetasi (2380.832 ha atau $66.819 \%$ dari total luas area), sedangkan luas terendah adalah kelas non vegetasi (75.737 ha atau $2.126 \%$ dari total luas area). Kelas kerapatan vegetasi dengan luas tertinggi pada tahun 2020 di TWA Sungai Dumai adalah kelas kerapatan vegetasi rapat (3205.039 ha atau 89.950 \% dari total luas area), sedangkan luas terendah adalah kelas non vegetasi (1.637ha atau $0.046 \%$ dari total luas area).

Kata kunci : Kerapatan vegetasi , NDVI, TWA Sungai Dumai

\section{PENDAHULUAN}

TWA (Taman Wisata Alam) Sungai

Dumai merupakan kawasan hutan wisata yang ditetapkan berdasarkan SK.Menhut No.154/Kpts-II/1990 Tanggal 10 April 1990 dengan luas kawasan 4.712,50 Ha. Kawasan ini terletak di wilayah Administrasi Kota Dumai Prov Riau. Secara Administrasi Kehutanan berada di bawah pengawasan Seksi Konservasi Wilayah III Bidang KSDA Wiayah II Balai Besar KSDA Riau. TWA Sungai Dumai ditetapkan sebagai hutan wisata karena memiliki karakteristik yang sesuai dengan kriteria hutan wisata dan dikelola juga sesuai dengan kebijakan pengelolaan TWA yang berlaku (Warsono et al. 2014).

Penetapan Kawasan Hutan Taman Wisata Alam (TWA) diantaranya karena memiliki panorama alam yang indah sehingga dapat dimanfaatkan bagi kepentingan pariwisata dan rekreasi alam.
Selain itu, kemudahan pencapaian lokasi, luas lahan yang menjamin kelestarian potensi alam dan kebijakan pemerintah ikut berperan dalam penetapan kawasan menjadi TWA (Imbiri, 2015). Akan tetapi, ada beberapa permasalahan yang dimiliki oleh TWA Sungai Dumai yang dapat mengganggu kelestarian sumberdaya alam, yaitu kebakaran hutan dan lahan (karhutla) dan alih fungsi lahan menjadi pertanian dan kebun sawit. Untuk permasalahan karhutla, berdasarkan laporan kinerja Direktorat Jenderal KSDAE (2018), TWA Sungai Dumai pernah menjadi wilayah kawasan konservasi tertinggi yang terbakar pada Tahun 2016 dengan luasan 2,432.02 Ha dari luas keseluruhan kawasan konservasi di Provinsi Riau yang terbakar yaitu 3,995.40 Ha. Hal tersebut tentu memiliki banyak dampak negatif, diantaranya terjadinya kerusakan dan pencemaran lingkungan hidup, seperti terjadinya 
kerusakan flora dan fauna, tanah, dan air yang sangat berbahaya bagi kawasan konservasi (Rasyid, 2014).

Selain kebakaran hutan dan lahan, alih fungsi lahan juga menjadi permasalahan di TWA Sungai Dumai. Alih fungsi lahan hutan menjadi lahan pertanian menimbulkan banyak masalah seperti penurunan kesuburan tanah, erosi, kepunahan flora dan fauna, banjir, kekeringan dan bahkan perubahan lingkungan global di TWA Sungai Dumai. Masalah ini bertambah berat dari waktu ke waktu sejalan dengan meningkatnya luas areal hutan yang dikonversikan menjadi lahan pertanian atau perladangan kelapa sawit. Untuk mengatasi permsalahan tersebut, Balai Besar Konservasi Sumber Daya Alam (BBKSDA) Riau merencanakan program kemitraan konservasi. Program ini mewadahi kelompok masyarakat yang diberikan izin untuk berkolaborasi bersama BBKSDA Riau untuk mengelola kawasan hutan yang merupakan upaya dalam merestorasi gambut bersama dengan BRG (Badan Restorasi Gambut) berupa praktek agroforestri. Selain itu, perlu adanya monitoring kerapatan vegetasi yang perlu dilakukan untuk mengamati kondisi vegetasi yang dimiliki TWA Sungai Dumai.

Vegetasi sebagai penyusun lahan pada TWA Sungai Dumai mempunyai jenis yang beraneka ragam. Pada setiap penggunaan lahan yang berbeda, kumpulan dari berbagai vegetasi yang beraneka ragam ini akan menghasilkan tingkat kerapatan vegetasi yang berbeda-beda (Purwanto, 2015). Teknik analisis vegetasi yang digunakan adalah menggunakan NDVI. Nilai NDVI sangat dipengaruhi oleh kerapatan vegetasi, tutupan tajuk dan jenis vegetasi, karena semakin rapat vegetasi dan tutupan tajuk maka permukaan daun akan memantulkan radiasi yang semakin besar. Vegetasi pepohonan akan memiliki nilai NDVI yang tinggi dibandingkan jika yang teridentifikasi berupa semak atau rumput (Dasuka et al., 2016). Kumpulan berbagai vegetasi yang beraneka ragam akan menghasilkan tingkat kerapatan vegetasi yang berbeda-beda pada tiap penggunaan lahan di suatu daerah (Lutfiah et al., 2017). Vegetasi memiliki ciri khas spektral yang unik dapat dianalisis dengan berbagai cara agar mendapatkan indeks yang mewakili kondisi dari vegetasi tersebut. Hingga saat ini, analisis vegetasi di TWA Sungai Dumai 
belum ada. Oleh karena itu, analisis vegetasi perlu dilakukan agar TWA Sungai Dumai dapat dikelola secara lestari.

Tujuan penelitian ini adalah untuk membuat klasifikasi kelas kerapatan vegetasi tahun 2017 dan 2020 yang disajikan berupa peta kelas kerapatan vegetasi di TWA Sungai Dumai, Riau tahun 2017 dan 2020.

\section{METODE PENELITIAN}

\subsection{Waktu dan Tempat}

Penelitian dilaksanakan dari bulan Mei sampai dengan November 2020. Tempat penelitian adalah TWA Sungai Dumai, Kota Dumai Provinsi Riau. Secara Geografis TWA Sungai Dumai terletak di 1 31'-1 38'LU dan 100 31'-101 28'BT. Pengolahan dan analisis data dilakukan di Laboratorium perencanaan dan manajemen hutan Fakultas Kehutanan Universitas Lancang Kuning.

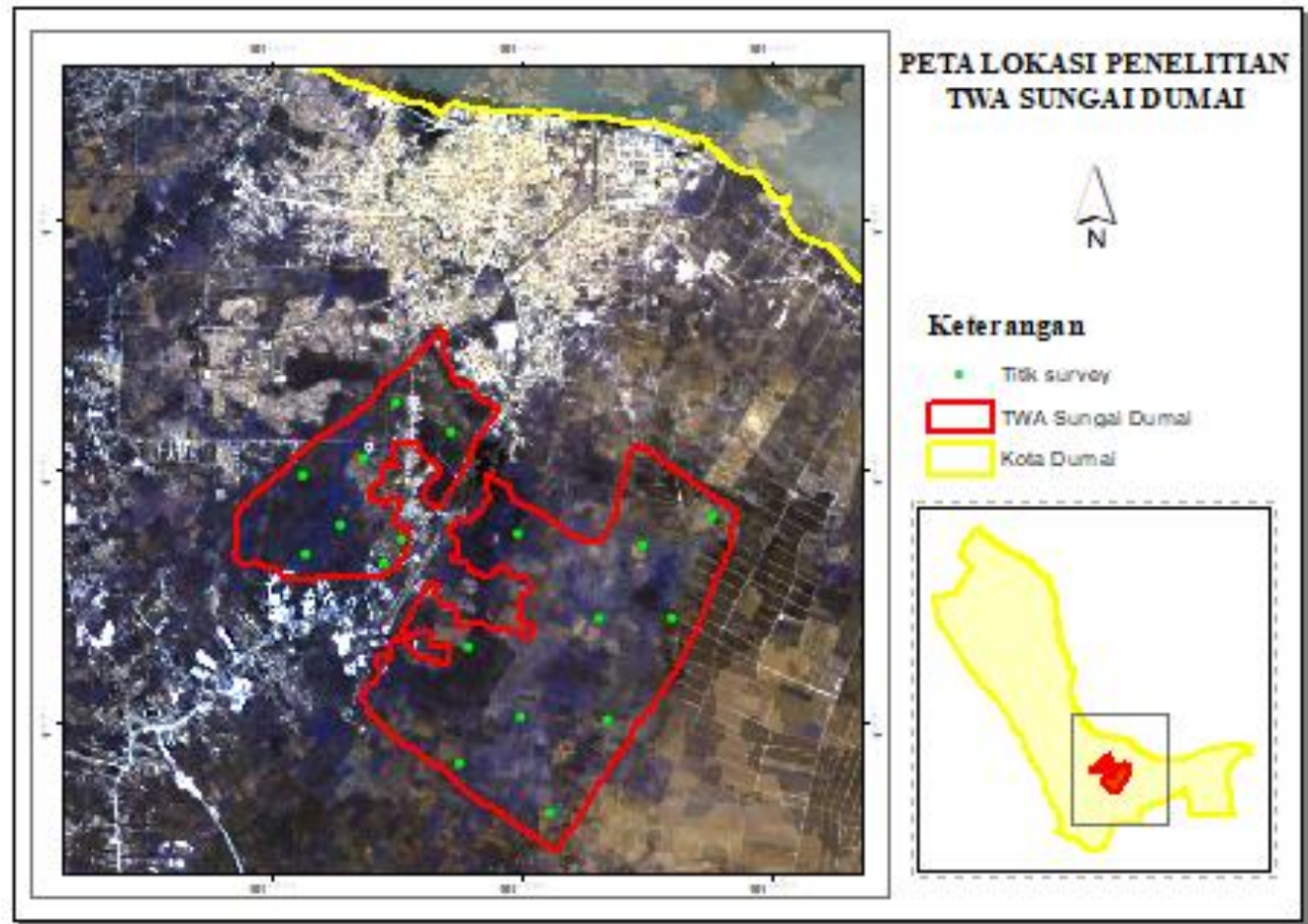

Gambar 1. Peta Lokasi Penelitian 


\subsection{Alat dan Data}

Alat yang digunakan berupa alat pengambilan data dan analisis data. Alat pengambilan data lapangan berupa GPS, kompas, kamera, alat tulis, dan lainnya. Alat dan software analisis data yang digunakan berupa Google Earth Engine (GEE), ArcGIS dan excel.

Bahan yang digunakan pada penelitian ini terdiri atas :

1. Citra Landsat- 8 OLI/TIRS Tahun 2020 Perekaman Oktober 2017 dan Oktober 2020.

2. Peta batas wilayah administrasi TWA Sungai Dumai.

3. Data lapangan berupa titik koordinat survey. Pengambilan data di lapangan dilakukan dengan menggunakan metode purposive sampling yang direncanakan berdasarkan kondisi tegakan yaitu sebanyak 18 titik yang tersebar merata di TWA Sungai Dumai.

\subsection{Prosedur Penelitian}

Tahap pengolahan menggunakan bahasa pemograman java script. Tahap pengolahan meliputi memasukan data citra satelit landsat 8 dan memasukan batas wilayah administrasi pada GEE.
Selanjutnya dilakukan filtering cloud masking pada citra untuk menghilangkan awan yang menutupi daerah penelitian. Citra satelit Landsat 8 yang digunakan sudah terkoreksi geometrik dan koreksi radiometrik BOA (Bottom Of Atmosphere) reflektan sehingga dalam penelitian ini tidak diperlukan koreksi kembali. Citra Landsat 8 yang digunakan perekaman bulan Oktober 2017 dan Oktober 2020. Koreksi atmosferik menggunakan algoritma SIAC pada GEE. Algoritma SIAC (Sensor Invariant Atmospheric Correction) ini menghasilkan koreksi atmosfer secara stabil (Hagolle et al., 2015).

Transformasi indeks vegetasi yang digunakan adalah algoritma NVDI (Normalized Difference Vegetation Index). Citra Landsat memiliki saluran band near infrared dan band red yang dapat membedakan kerapatan vegetasi dan lahan terbuka.Perhitungan NDVI didapatkan dari selisih normalisasi antara band red dan band near infrared dibagi dengan jumlah kedua band tersebut pada citra. Algoritma NDVI dapat dilihat pada persamaan (1). Nilai dari NDVI berkisar dari -1 hingga +1 dengan semakin tinggi nilai NDVI maka akan semakin tinggi kerapatan vegetasinya. 
Selanjutnya akan didapatkan hasil analisis kerapatan vegetasi dengan rentang klasifikasi merujuk pada Al-Doski et al. (2013) yang ditampilkan pada Tabel 1.

Tabel 1. Klasifikasi NDVI

\begin{tabular}{|c|c|}
\hline Rentang klasifikasi & Jenis kerapatan \\
\hline$-1 \leq \mathrm{NDVI}<0,2$ & Non vegetasi \\
$0,2<\mathrm{NDVI}<0,4$ & Vegetasi jarang \\
$0,4<\mathrm{NDVI}<0,6$ & Vegetasi sedang \\
$0,6<\mathrm{NDVI} \leq 1$ & Vegetasi rapat \\
\hline
\end{tabular}

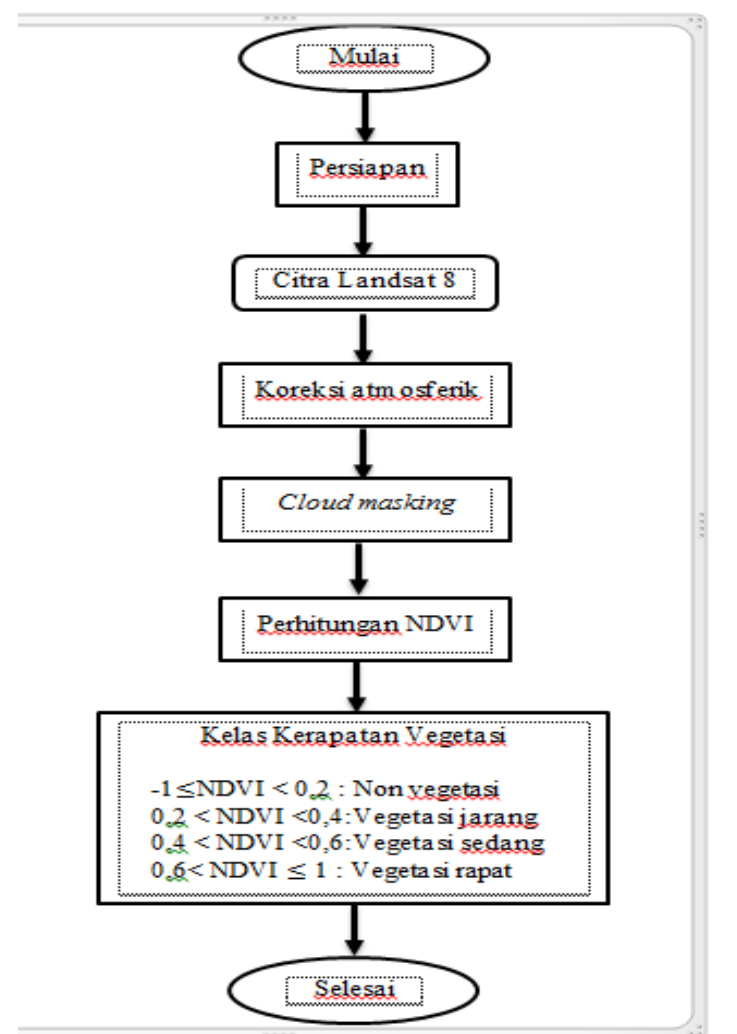

Gambar 2. Prosedur Penelitian

\section{HASIL DAN PEMBAHASAN}

Analisis

kerapatan

vegetasi

menghasilkan sebaran nilai NDVI di TWA Sungai Dumai, Riau. Hasil pengolahan dibagi menjadi 4 kelas yaitu kelas non vegetasi, jarang, sedang dan rapat dengan luas yang berbeda pada setiap kelasnya. Nilai NDVI pada kelas kerapatan vegetasi di TWA Sungai Dumai Tahun 2017 dan 2020 dapat dilihat pada Tabel 2 dan Gambar 2. 
Tabel 2. Nilai NDVI dan Kelas Kerapatan Vegetasi di TWA Buluh Cina Tahun 2017 dan 2020

\begin{tabular}{|l|l|l|l|l|l|l|}
\hline \multirow{2}{*}{ No } & \multirow{2}{*}{ Kerapatan vegetasi } & \multirow{2}{*}{ NDVI } & \multicolumn{2}{c|}{ Tahun 2017} & \multicolumn{2}{c|}{ Tahun 2020 } \\
\cline { 4 - 7 } & & & Luas (Ha) & $\%$ & Luas (Ha) & \multicolumn{1}{c|}{$\%$} \\
\hline 1 & Non vegetasi & $<0,2$ & 75.737 & 2.126 & 1.637 & 0.046 \\
\hline 2 & Vegetasi jarang & $0,2-0,4$ & 712.379 & 19.993 & 21.266 & 0.597 \\
\hline 3 & Vegetasi sedang & $0,4-0,6$ & 2380.832 & 66.819 & 335.182 & 9.407 \\
\hline 4 & Vegetasi rapat & $>0,6$ & 394.176 & 11.063 & 3205.039 & 89.950 \\
\hline \multicolumn{2}{|l}{ Total } & & 3563.124 & 100 & 3563.124 & 100 \\
\hline
\end{tabular}

Berdasarkan tabel 1 dapat diketahui bahwa nilai maksimal > 0.6 dari algoritma NDVI di kawasan TWA Sungai Dumai menunjukkan bahwa tingkat kehijauan tanaman di daerah tersebut tinggi. Nilai minimum $<0,2$ menunjukkan bahwa daerah tersebut memiliki tingkat kehijauan tanaman sangat rendah.

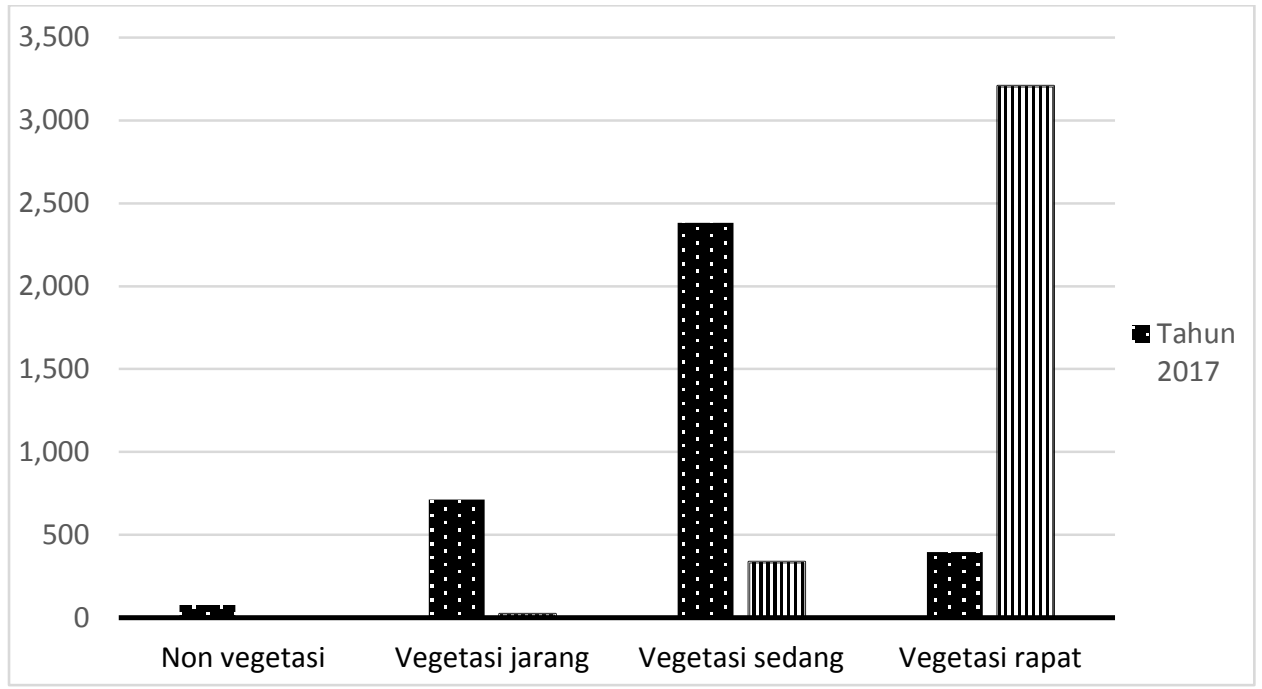

Gambar 2. Sebaran Kerapatan Vegetasi di TWA Buluh Cina Tahun 2017 dan 2020

Perubahan luas kerapatan vegetasi tahun 2017 dan tahun 2020 dipengaruhi oleh perambahan hutan, kebakaran hutan dan lahan hingga pemulihan kondisi hutan dengan penerapan agroforestri. Kawasan TWA Sungai Dumai pada tahun 2017 yang memiliki luasan tertinggi ada pada kelas kerapatan vegetasi sedang (2380.832 ha). Perambahan hutan hingga kebakaran hutan dan lahan pada tahun 2016 menyebabkan terjadinya penurunan tutupan hutan dari kerapatan tinggi menjadi kerapatan sedang. 
Adanya aksesbilitas tinggi di dalam hutan dapat mendorong dan memicu manusia untuk mengubah penggunaan hutan dan lahan hingga deforestasi hutan (Setiawan et al. 2016; Zaitunah et al. 2018). Pengalihan fungsi hutan untuk penggunaan lain sudah terbukti sebagai ancaman terhadap keberadaan wilayah hutan. Sedangkan, luasan terendah pada kelas kerapatan vegetasi tahun 2017 di TWA Sungai Dumai adalah non vegetasi (75.737 ha). Jika dibandingkan dengan kelas kerapatan vegetasi yang lain, kelas non vegetasi memiliki luas terendah dan cenderung tidak akan mengalami perubahan yang signifikan hingga 5-10 tahun berikutnya. Hal ini dikarenakan lahan yang tidak memiliki vegetasi cenderung akan menjadi lahan perkebunan illegal masyarakat atau lahan tertinggal begitu saja hingga kegiatan reboisasi dilakukan. Pembukaan hutan hingga kebakaran hutan juga digunakan untuk membuka lahan menjadi perkebunan setelah areal hutan menjadi terbuka (Murniati et al. 2008). Serta lahan terbuka tersebut dapat juga dialihfungsikan menjadi lahan usaha lain secara illegal (Widianto et al. 2003).
Untuk luasan kelas kerapatan vegetasi tertinggi tahun 2020 di TWA Sungai Dumai adalah pada kelas kerapatan vegetasi rapat (3205.039 ha). Adanya kerjasama BBKSDA Riau bersama masyarakat untuk mengelola hutan menggunakan sistem agroforestri mampu meningkatkan luasan kelas kerapatan vegetasi jarang dan sedang menjadi rapat. Agroforestri dapat menjadi solusi untuk masalah deforestrasi dan degradasi hutan (Niemmanee et al. 2015). Berdasarkan kegiatan survei di lapangan (Tabel 3), pada kelas kerapatan tinggi juga tidak hanya ditemui pepohonan, tetapi juga ditemukan jenis tanaman sawit. Hal ini juga diduga menjadi penyebab perubahan luasan kelas kerapatan vegetasi tertinggi tahun 20172020 terdapat pada kelas kerapatan vegetasi rapat. Pemanfaatan citra landsat juga belum dapat membedakan jenis vegetasi di suatu hamparan lahan, sehingga terdapat indikasi pada kelas kerapatan vegetasi rapat ini tidak hanya ada pohon, tetapi juga terdapat jenis tumbuhan lainnya (Desuka et al. 2016). Untuk luasan kelas kerapatan vegetasi terendah ada pada kelas non vegetasi. peta kerapatan vegetasi TWA Sungai Dumai tahun 2017 disajikan pada Gambar 3 dan 
peta kerapatan vegetasi TWA Sungai

4.

Dumai tahun 2020 disajikan pada Gambar

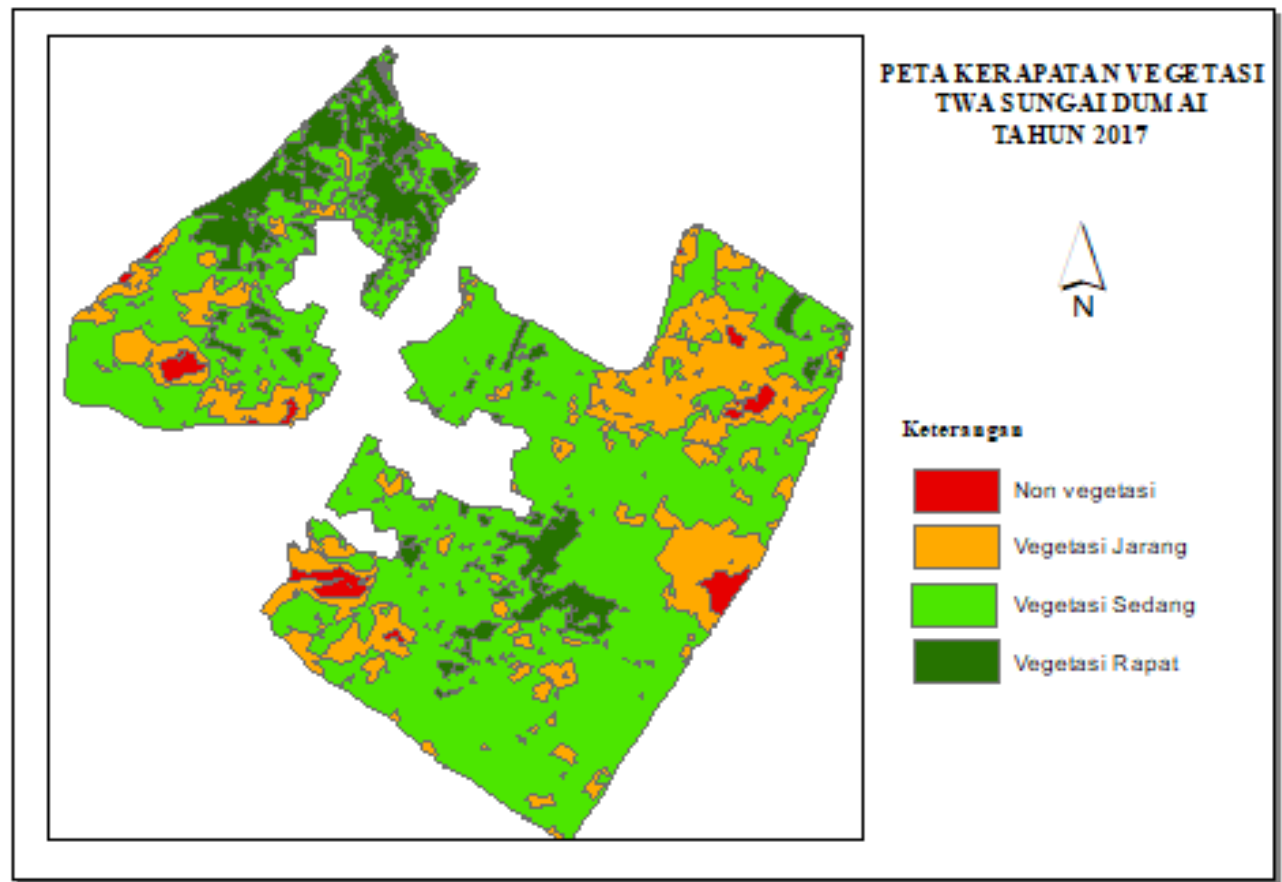

Gambar 3. Peta sebaran kerapatan vegetasi di TWA Sungai Dumai Tahun 2017

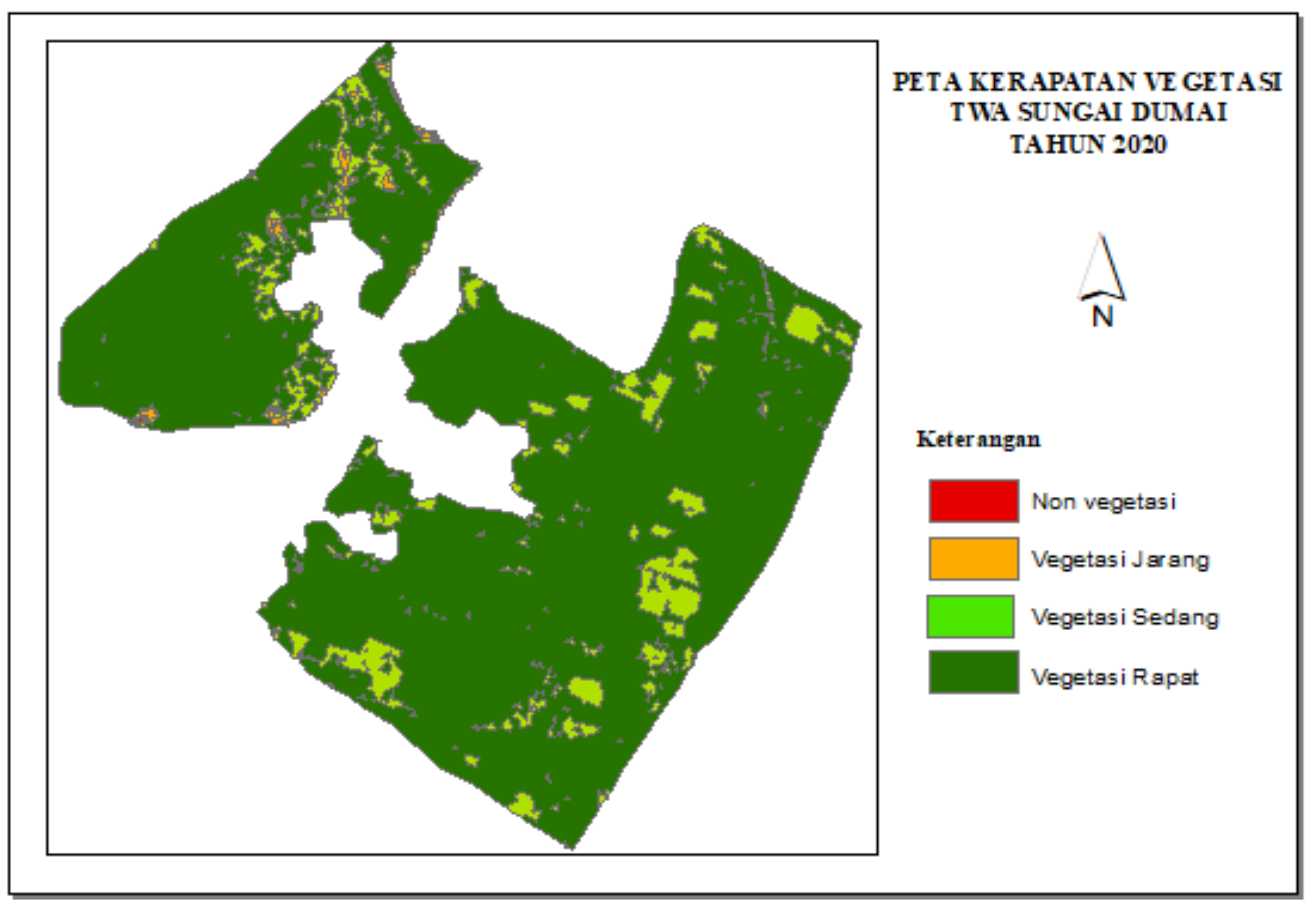

Gambar 4. Peta sebaran kerapatan vegetasi di TWA Sungai Dumai Tahun 2020 
Tabel 3. Gambar perbandingan visualisasi kelas kerapatan

\begin{tabular}{|l|l|l|c|c|c|}
\hline No & $\begin{array}{c}\text { Kelas } \\
\text { kerapatan }\end{array}$ & Citra NDVI & Peta kerapatan & Lapangan \\
\hline 1 & $\begin{array}{l}\text { Non } \\
\text { vegetasi }\end{array}$ & & & & \\
\end{tabular}

\section{KESIMPULAN DAN SARAN}

\section{A. Kesimpulan}

Berdasarkan hasil penelitian dan uraian pembahasan dapat diambil kesimpulan sebagai berikut:

1. Analisis kerapatan vegetasi menggunakan citra Landsat 8 dengan algoritma NDVI di TWA Sungai Dumai tahun 2017 dan tahun 2020 menghasilkan 4 kelas kerapatan vegetasi, diantaranya kelas kerapatan non vegetasi, vegetasi jarang, vegetasi sedang dan vegetasi rapat.

2. Kelas kerapatan vegetasi dengan luas tertinggi pada tahun 2017 di TWA 
Sungai Dumai adalah kelas kerapatan vegetasi sedang dengan luas 2380.832 ha atau $66.819 \%$ dari total luas area, sedangkan luas terendah kelas kerapatan vegetasi pada tahun 2017 di TWA Sungai Dumai adalah kelas non vegetasi dengan luas 75.737 ha atau $2.126 \%$ dari total luas area TWA Sungai Dumai.

3. Kelas kerapatan vegetasi dengan luas tertinggi pada tahun 2020 di TWA Sungai Dumai adalah kelas kerapatan vegetasi rapat dengan luas 3205.039 ha atau $89.950 \%$ dari total luas area, sedangkan luas terendah kelas kerapatan vegetasi pada tahun 2020 di TWA Sungai Dumai adalah kelas non vegetasi dengan luas 1.637ha atau $0.046 \%$ dari total luas area TWA Sungai Dumai.

\section{B. Saran}

Diperlukan analisis lebih lanjut menggunakan citra resolusi tinggi untuk menghasilkan data yang lebih detail.

\section{DAFTAR PUSTAKA}

Al-Doski, J., Mansor, S.B \& Shafri, H.Z.M. (2013). NDVI differencing and post-classification to detect vegetation changes in Halabja City, Iraq. IOSR Journal of Applied Geology and Geophysics, I(2), 01-10.

Dasuka, Y.P., Sasmito, B \& Hani'ah. (2016). Analisis jenis vegetasi hutan alami menggunakan sistem penginderaan jauh (Studi kasus : jalur pendakian wekas dan selo). Jurnal Geodesi Undip, V(2), 1-8.

Direktorat Jenderal KSDAE. (2018). Laporan Kinerja Direktorat Jenderal KSDAE Tahun 2017. Jakarta

Hagolle, O., Huc, M., Pascual, D \& Dedieu, G. (2015). A multi-temporal and multi-spectral method to estimate aerosol optical thickness over land, for the atmospheric correction of FormoSat-2, LandSat, VENS an sentinel-2 images. Remote Sensing, 7(3):2668-2691.

Imbiri, S. (2015). Pengelolaan kawasan hutan Taman Wisata Alam Gunung Meja di Kabupaten Manokwari. Jurnal Kehutanan Papuasia, 1(1), 36-52.

Lutfiah, S.N., Makalew, A.D.N \& Sulistyantara, B. (2017). Pemanfaatan citra Landsat 8 untuk analisis indeks vegetasi di DKI Jakarta. Jurnal Landskap Indonesia, 9(1), 73-80. 
Murniati., Nawir., Rumboko. (2008). Rehabilitasi Hutan Indonesia. CIFOR. Bogor.

Niemmanee, T., Kaveeta, R., Potchanasin, C. (2015). Assessing The Economic, Social, And Environmental Condition For The Sustainable Agricultural System Planning In Ban Phaeo District, Samut Sakhonn Province, Thailand. Jurnal Elsevier ScienceDirect, 197(2015), 2554 2560.

Purwanto, A. (2015). Pemanfaatan citra Landsat 8 untuk identifikasi Normalized Difference vegetation Index (NDVI) di Kecamatan Silat Hilir Kabupaten Kapuas Hulu. Jurnal Edukasi, 13(1), 27-36.

Rasyid, F. (2014). Permasalahan dan dampak kebakaran hutan. Jurnal Lingkar Widyaiswara, 1(4), 47-59.

Warsono, Soetriono, Januar, J. (2014). Strategi pemberdayaan masyarakat sekitar hutan konservasi Taman Wisata Alam Gunung Baung dalam upaya mengurangi perambahan hutan. JSEP, 7(2), 6270.

Widianto., Suprayogo., Purnomosidi., Widodo., Rusiana., Aini., Khasanah., Kusuma. (2004). Degradasi Sifat Fisik Tanah Sebagai Akibat Alih Guna Lahan Hutan Menjadi Sistem Kopi Monokultur: Kajian Perubahan
Makroporositas Tanah. Jurnal Agrivita, 26(1), 47-52.

Zaitunah, A., Samsuri., Ahmad, A.G., Safitri, R.A. (2018). Normalized difference vegetation index (NDVI) Analysis for Land Cover Types Using Landsat 8 Oli in Besitang Watershed, Indonesia. Friendly city 4 'From Research To Implementation For Better Sustainability'. IOP Publishing, 126: 1-10. 